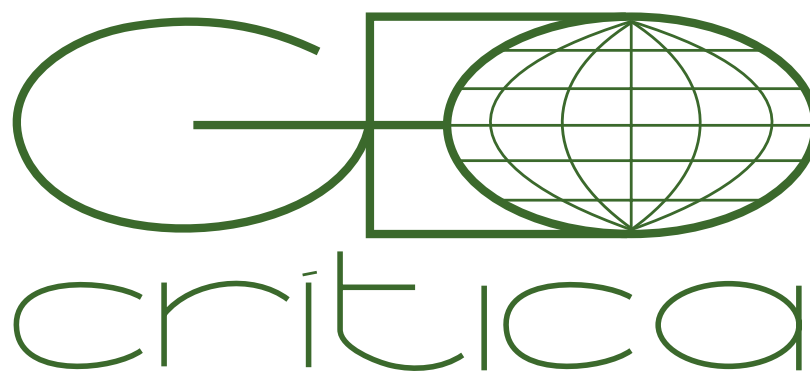

\section{Scripta Nova}

Revista Electrónica de Geografía y Ciencias Sociales Universidad de Barcelona

15 de marzo de 2017

\title{
ESTRATEGIAS DE RENOVACIÓN DE BARRIOS INDUSTRIALES EN CIUDADES MEDIAS ESPAÑOLAS. LA EXPERIENCIA DE LEÓN
}

\author{
Paz Benito del Pozo \\ Departamento de Geografía y Geología \\ Universidad de León \\ paz.benito@unileon.es \\ Francisco Diez Vizcaíno \\ Departamento de Geografía y Geología \\ Universidad de León
}

Recibido: 13/12/2015; Devuelto para revisión: 10/06/2016; Aceptado: 17/10/2016

\begin{abstract}
Estrategias de renovación de barrios industriales en ciudades medias españolas. La experiencia de León (Resumen)

Análisis de la transformación de barrios industriales en ciudades medias españolas a partir del caso de León, en el norte peninsular. El objetivo se centra en las estrategias e instrumentos de los agentes públicos para sustituir los usos y funciones tradicionales por otros relacionados con la nueva economía y competitividad urbana. Con enfoque histórico se revisa la formación del llamado León Oeste, una zona donde las fábricas y el ferrocarril impulsaron el cambio urbano en la etapa del industrialismo. La crisis del modelo fordista desencadenó la desindustrialización de este barrio, un reto para la planificación urbana y un negocio para los agentes implicados en la producción de suelo. Como solución, se plantean intervenciones urbanísticas que responden al doble fin de crear focos de centralidad alternativos y oportunidades que dependen de la especialización terciaria y de la alta velocidad ferroviaria, opciones no exentas de riesgos y que tienen como trasfondo la burbuja inmobiliaria que lastra el proceso de urbanización español desde 2008.
\end{abstract}

Palabras clave: gentrificación en ciudades medias, renovación urbana, integración ferroviaria, fábricas abandonadas, León.

Strategies renovation of industrial neighborhood in Spanish medium-sized cities. The experience of León (Abstract)

Analysis of the transformation of industrial neighborhood in Spanish medium cities from the case of Leon in northern Spain. The focus is on the strategies and instruments of public officials to replace traditional uses and functions related to the new economy and urban competitiveness. With the formation of the

Este trabajo forma parte de los resultados del Proyecto de Investigación I+D de Excelencia, Ministerio de Economía y Competitividad, Subprograma de Generación de Conocimiento, convocatoria 2013. Referencia CSO2013-447205-P. historical approach called Leon West, where factories and railway boosted the urban change in the stage of industrialism is reviewed. The crisis of the Fordist model triggered the deindustrialization of the neighborhood, a challenge for urban planning and business for those involved in the production floor. As a solution, urban interventions that respond to the dual purpose of creating pockets of alternative centrality and opportunities depend on the tertiary specialization and high-speed rail, options not without risks and whose background the housing bubble that hampers the Spanish process of urbanization since 2008.

Keywords: gentrificación in medium-sized cities, urban regeneration, railway integration, abandoned factories, León. 
Se plantea una investigación en materia de geografía urbana acerca del significado y el alcance de la renovación de barrios industriales abandonados, degradados y marginales, pero con una posición en la trama urbana que les otorga centralidad y rasgos de elevada competitividad, lo que los agentes públicos aprovechan, con el apoyo de constructores y del sector financiero, para ejecutar intervenciones urbanísticas drásticas que implican sustituir el modelo de ciudad industrial consolidado en la primera mitad del siglo XX por otro basado en la gentrificación, la ampliación de la oferta de suelo residencial de calidad y la multiplicación de actividades terciarias identificadas con la nueva economía urbana y alojadas en contenedores cuya estética, de rehabilitación o de nueva edificación, responde a una estrategia de marketing que anula o neutraliza el discurso oficial en favor, entre otros, del patrimonio urbano y la defensa del valor simbólico de ciertos espacios y construcciones de la ciudad.

Con una metodología cualitativa y centrada en la revisión bibliográfica, las labores de documentación, el trabajo de campo y el análisis cartográfico, se estudia el sector oeste de la ciudad de León, asimilable a los barrios industriales históricos de la mayoría de las ciudades medias españolas y europeas, pero con la singularidad de ofrecer dos actuaciones urbanísticas emblemáticas que sintetizan las claves de la renovación de la ciudad postindustrial y apuntan a la gentrificación como fenómeno dominante. Las intervenciones consisten a) en la reutilización de los terrenos y edificios de la fábrica de azúcar Santa Elvira, herencia de la industrialización histórica, y b) en la reordenación y modernización de las infraestructuras ferroviarias ligadas a esa y otras factorías del entorno. Una detallada cartografía de elaboración propia es el recurso elegido para mostrar la secuencia temporal de las transformaciones y su significado espacial. Asimismo el enfoque histórico permitirá explicar la formación del barrio ferroviario e industrial León Oeste y comprender el alcance y significado de la estrategia de renovación en marcha, afectada, como se verá, por el estallido de la burbuja inmobiliaria y la crisis financiera.

La hipótesis es que aunque en apariencia en las ciudades medias se respeta el legado de la industrialización histórica -nivel del discurso político, adaptado a la creciente sensibilidad social hacia el patrimonio industrial y los paisajes urbanos heredados-, los hechos que evidencian el planeamiento urbano y las intervenciones urbanísticas ejecutadas traslucen la concurrencia de intereses públicos y privados para transformar, con la lógica del mercado, un sector tradicional de la ciudad en un barrio adaptado morfológica, estética y funcionalmente a las exigencias de la globalización, el marketing y la competitividad urbana. Asimismo, se tratará de demostrar que la experiencia de León se encuadra en el proceso urbanizador que tiene lugar en España desde finales de la década de 1990 hasta la actualidad, con el trasfondo de la burbuja inmobiliaria que se hace evidente en 2008 y que será la causa directa de una crisis cuyo impacto alcanza de lleno a los barrios industriales en proceso de renovación y gentrificación, lo que a su vez influye en la gobernanza de la ciudad, tal y como se recoge en numerosos trabajos publicados desde 2010. 


\section{Procesos y debates sobre la ciudad industrializada y su transformación}

En las ciudades europeas que participaron del industrialismo este proceso de transformación radical de la economía y la sociedad dejó su huella en la trama urbana, fraguada por el ferrocarril, las fábricas y las viviendas obreras, y condicionó su desarrollo a lo largo del siglo XIX y primera mitad del siglo XX. La morfología resultante de la presencia masiva de la industria en la ciudad y paisaje asociado a la misma, marcado por la mezcla caótica de fábricas humeantes, densos y ortopédicos trazados ferroviarios, barrios marginales y, en su caso, zonas portuarias de frenética actividad, se irán transformando a medida que avanza y se consolida el proceso de periferización de la industria y, con ello, una mayor regulación de los usos del suelo y una creciente preocupación pública por la calidad del ambiente urbano En efecto, el traslado a espacios extraurbanos o periféricos de la industria, una vez concluida la fase histórica de industrialización, representa un punto de inflexión, una nueva etapa de transformación urbana que implica el abandono de los recintos industriales tradicionales en favor de espacios delimitados y sometidos a la lógica de la planificación urbanística, que crea espacios delimitados (los llamados polígonos industriales) para usos exclusivamente productivos fuera de las áreas centrales y cada vez más alejados de los barrios residenciales, en una suerte de "expulsión" que no pone fin a la industria urbana, pero sí acredita el final de un modelo ya que las actividades empresariales de tipo industrial seguirán ligadas a la ciudad, pero según nuevas pautas urbanísticas que dictan una distancia estratégica entre los establecimientos productivos y las áreas residenciales, en aras de la compatibilidad de usos del suelo, aunque también por la presión inmobiliaria y por el imperativo de más sostenibilidad, en términos de calidad del ambiente urbano y una vida saludable, retos que habrán de asumir los responsables de la gobernanza urbana al comenzar el siglo XXI en el escenario crea do por la globalización económica En el contexto de las ciudades pequeñas y medias españolas, la industrialización, tardía y débil en general también desencadenó procesos que expresan, en primera instancia, el impacto de las fábricas en la estructura y desarrollo urbano y, en segundo lugar, el posterior traslado a las afueras de las fábricas y actividades a ellas ligadas, con la consiguiente presencia residual de factorías y naves industriales en espacios centrales y de borde llamados a desempeñar una función de centralidad por el avance de nuevos usos y actividades desde finales del siglo XX y principios de la centuria actual, a semejanza de lo que había acontecido unas décadas antes en las grandes ciudades del país, como Barcelona, Madrid o Bilbao.

Este fenómeno es responsable de la formación de lo que se denominan "vacíos industriales" y dará pie a una estrategia orientada a la renovación y recualificación urbana que tiene como argumento fundamental la mejora de la competitividad de las ciudades, en pugna unas con otras por tomar posiciones de ventaja en un contexto de ciudad postindustrial. 


\section{Sobre viejas fábricas, recintos industriales obsoletos y ferrocarril: ¿oportunidad o problema urbano?}

Mientras las corporaciones locales tratan de dar respuesta a los desafíos que plantean las pautas de localización de la industria en el contexto de la globalización (con soluciones que se traducen en una proliferación de parques empresariales y tecnológicos extraurbanos y periurbanos, en su mayoría de promoción pública y diseñados en función de las políticas industriales y de ordenación del territorio que dictan los Gobiernos autonómicos o locales), surge un nuevo eje de discusión en torno a las fábricas que perviven en la ciudad como parte de la herencia del industrialismo: conservar versus destruir, dar valor patrimonial a un legado que la propia Unesco defiende como patrimonio cultural (en el año 1994 una fábrica siderúrgica alemana es declarada Patrimonio Mundial, y así hasta más de 20 sitios industriales y mineros en la actualidad) o bien aprovechar las ventajas de renta de los recintos industriales abandonados para nuevos desarrollos urbanísticos y dotar así al caduco espacio industrial de nuevas funciones tal y como ocurrió en Glasgow y Bilbao. En los albores del siglo XXI no parece defendible que la solución al desafío de las ruinas industriales pase por arrasar sin más con un legado que puede merecer la consideración de bien cultural o de símbolo de una etapa de la historia de la ciudad (la bibliografía generada desde 1996 por el TICCIH es elocuente de la densidad de este debate y del éxito de múltiples acciones de protección, conservación y puesta en valor del patrimonio industrial, tanto en Europa como en América y Asia ).

Ahora bien, la defensa de las viejas fábricas no siempre responde a una posición de compromiso con el patrimonio industrial, es decir, con la defensa de la historia industrial y su legado más representativo en cada lugar. Algunos autores afirman en los años de 1980 que se trata de una defensa interesada, que surge en momentos de crisis, cuando la desaparición de las actividades tradicionales (textil, siderurgia, minería) y el posterior fracaso de otras alternativas fuerzan a una comunidad a buscar vías de escape; y el patrimonio industrial como recurso urbano es una de ellas. Otros autores van más allá y sostienen que la conservación y recuperación de este patrimonio obedece a intereses especulativos: "Desde finales del siglo XX la ciudad ha venido realizando un enorme esfuerzo para desarrollar estrategias competitivas con las que asegurarse una posición preeminente en el conjunto del sistema. Con tal objeto se han empleado agresivas técnicas de cirugía estética y profundos tratamientos cosméticos, encaminados a prolongar la actividad de un sinfín de espacios y contenedores y a rentabilizarlos después, utilizando diversas técnicas de promoción y venta de la nueva-vieja ciudad" Otra línea de interpretación, menos crítica, pone el acento en el interés urbanístico de los terrenos liberados por la industria, que pueden destinarse a nuevos usos que revitalicen la ciudad y generen oportunidades; este enfoque deriva y se aplica a la experiencia de ciudades que han desmantelado sus instalaciones industriales con el resultado de una importante bolsa de suelo vacante que representa, en sí misma, un desafío urbanístico y un recurso para crear 
nuevos espacios de centralidad y desarrollar o potenciar funciones urbanas alternativas, en particular las relacionadas con el turismo y la cultura. En este marco de debates múltiples y cruce de enfoques, unos más idealistas y otros más pragmáticos o críticos, hay que situar la intervención de los agentes públicos en ciudades medias donde la huella de la industrialización ha dejado fábricas cuya consideración social ha variado con el paso del tiempo, transitando desde la indiferencia o el rechazo hasta la defensa y reutilización de las mismas. El caso de la ciudad de León que aquí nos ocupa ofrece el ejemplo de la azucarera Santa Elvira, intervenida en estos últimos años y todavía en proceso de rehabilitación para adaptarla a usos de palacio de congresos y exposiciones, una intervención que adquiere pleno valor de representación en el análisis de las relaciones entre industria y ciudad, pues ilustra la paradoja de las fábricas poco apreciadas como patrimonio, pero rescatadas de la ruina con fines utilitarios.

Como se tratará de demostrar, esta fábrica es un ejemplo de intervención especulativa, enmascarada bajo el discurso oficial del patrimonio industrial, un fenómeno identificado y descrito en numerosas ciudades españolas Por su parte, la integración del ferrocarril y la llegada del tren de alta velocidad en el entorno de la azucarera es elocuente de la doble estrategia pública de mejorar, por un lado, las condiciones de León para tener éxito en la búsqueda de oportunidades a escala metropolitana y regional; y de crear, por otro lado, nuevas centralidades. Sobre la importancia histórica del ferrocarril en la transformación de las ciudades medias, la literatura abunda en la idea de su capacidad para generar efectos positivos, como la extensión de redes de servicios urbanísticos, la revalorización del precio del suelo o la mejora de la accesibilidad, pero también en sus efectos indeseables, entre los que destaca la creación de barreras urbanas un problema de primer orden desde el punto de vista de la expansión de la trama y del desarrollo urbanístico que en la mayoría de los casos se ha resuelto trasladando las vías al exterior o mediante el soterramiento, soluciones ambas que llevan aparejado un áspero conflicto entre los intereses municipales y Adif-Renfe.

La alta velocidad, asimismo, añade tensión a las relaciones entre ciudad y ferrocarril puesto que los requerimientos técnicos de los nuevos trenes deben hacerse compatibles con la pretensión de los responsables públicos de mantener la presencia de la moderna estación en el centro de la ciudad, pues actúa como un imán de múltiples oportunidades. De hecho, como señalan algunos autores, “su integración sobre el medio urbano consolidado requiere de intervenciones más complejas y sofisticadas, que en muchos casos acaban significando auténticos proyectos de renovación urbana" 


\section{Factores históricos del desarrollo industrial de León: patrón clásico y rasgos singulares}

\section{El ferrocarril: vector urbanístico e imán de la industria}

En el contexto de los cambios y transformaciones profundas que experimentan las economías europeas durante el último tercio del siglo XVIII y a lo largo del XIX al socaire de la Revolución Industrial, la España interior se perfila como un espacio eminentemente agrario, donde la mecanización de la industria no es un factor suficiente para desencadenar transformaciones profundas y rápidas, ni para propiciar un desarrollo urbano de grandes dimensiones. La aproximación al caso de León confirma la acusada ruralidad de los núcleos urbanos y ciudades de la Meseta norte, e incluso su atraso y relativo estancamiento en estos años En 1863 la llegada del ferrocarril alteró el patrón preindustrial de crecimiento de esta ciudad, que con apenas 10.000 habitantes y una economía de base agraria, encontrará en el nuevo modo de transporte un factor de modernización e industrialización, igualándose en esto al resto de las pequeñas y medias ciudades españolas y, entre ellas, a las más aventajadas de su entorno inmediato (Valladolid y Burgos). Un cambio cualitativo que algunos autores sintetizan en la idea de que en León el ferrocarril no solo permitió vertebrar y comunicar el territorio circundante, y con ello desenclavar la ciudad, sino que también fue un imán para la industria y una herramienta de difusión del comercio.

El primer tren llegó oficialmente en 1863; sin embargo, hay que retroceder hasta el 16 de febrero de 1861 para fijar el primer hito de la historia ferroviaria de la ciudad, cuando el Gobierno concede los dos primeros tramos de la línea Palencia - León y León - Ponferrada a Acisclo Miranda e hijo Desde el punto de vista urbanístico, el ferrocarril no alteró sustancialmente la morfología de la ciudad ya que se localizó lejos de la trama consolidada, aunque los cambios que desencadenó el proceso de crecimiento asociado a la presencia del tren propiciaron la paulatina desaparición de los elementos defensivos y de cierre y control de la ciudad, las murallas, a la vez que se habilitaban nuevas puertas y calles. Concretamente la estación de tren se ubicó en la margen derecha del río Bernesga, opuesta a la que ocupa la ciudad histórica, y la tentación de colonizar el espacio intermedio, un impulso novedoso y audaz por la desprotección que en el pasado suponía vivir fuera de las murallas, se intensificó. En consecuencia, las primeras decisiones estratégicas de las autoridades municipales fueron: una, proyectar la construcción de un puente sobre el río Bernesga (1863) y, dos, planificar en 1864 el trazado de una nueva vía que conectase ciudad y ferrocarril (calle Las Negrillas, después Ordoño II), iniciativas ambas que traslucen una nueva relación territorial entre la ciudad heredada y el espacio urbano presidido por el ferrocarril (figura 1). 


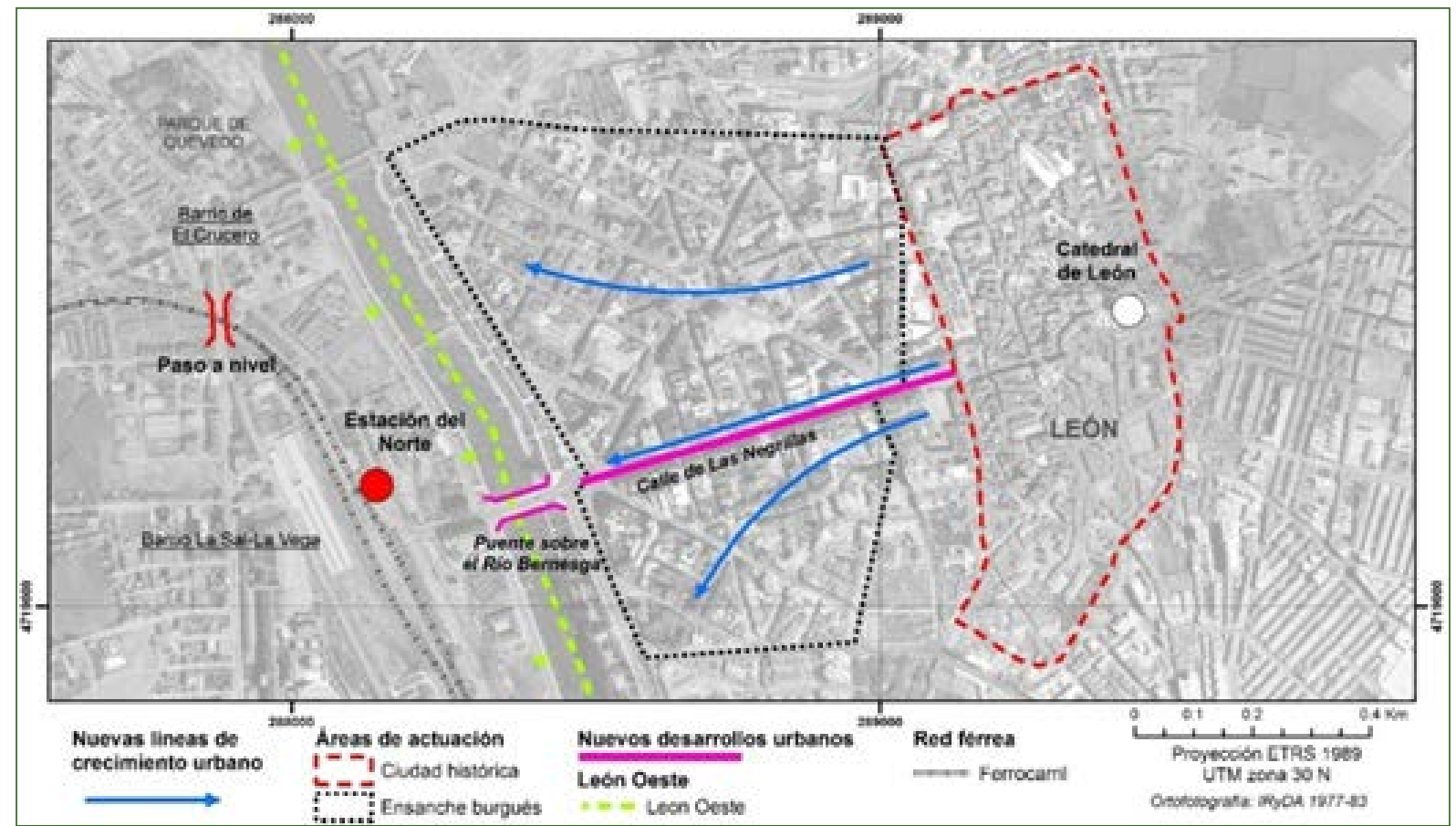

Figura 1.Interpretación de las transformaciones inducidas por el ferrocarril en el León decimonónico e industrial

Fuente: Elaboración propia.

La influencia del ferrocarril se pone asimismo de manifiesto en dos hechos relevantes desde el punto de vista del desarrollo de la trama urbana. El primero es la creación de barrios obreros en los arrabales que se extienden más allá del casco histórico (barrio de San Lorenzo) y con especial intensidad en los aledaños de la estación de trenes (barrios de la Sal y de El Crucero); y el segundo es el diseño y presentación en 1897 del Plan de Ensanche de la Ciudad de León, aprobado en 1904 (Figura 1). Además, el ferrocarril actuó como factor de industrialización y a su alrededor se van asentando de forma diseminada importantes factorías, entre otras la Papelera Leonesa (1900), la empresa de aceites Elosúa (1927), la química UQESA-Abelló (1933) y la Azucarera Santa Elvira (1934), formando una suerte de eje industrial que se prolonga hasta la fábrica de Antibióticos (1951). Aunque se trata de una industrialización débil, es elocuente del proceso general en el que está inmersa la ciudad y del fenómeno de formación de un paisaje urbano-industrial que expresa la modernización de León en sintonía con otras ciudades de su tamaño

\section{La producción de azúcar como seña de identidad urbana}

La producción del azúcar será la actividad que marque más intensamente el carácter industrial del sector oeste de León y su dependencia del ferrocarril. Aunque fue en 1935 cuando se puso en marcha la Azucarera Santa Elvira por iniciativa de la Sociedad Industrial Castellana, SA, hubo intentos anteriores, como el protagonizado por la sociedad anónima Azucarera La Bernesga, 
constituida el 10 de mayo de 1900 y cuya actividad inicial se centraba en la fabricación de azúcar de remolacha, compra de las materias necesarias para esta industria y venta de productos, no llegándose a alcanzar estos objetivos. La Sociedad Industrial Castellana construyó su factoría de azúcar en una parcela de más de 20 hectáreas de suelo junto a la estación de ferrocarril (figura 2), buscando una situación rentable para el movimiento de materias primas y mercancías y en una zona obrera consolidada (barrios de La Sal, La Vega y El Crucero). La preparación del terreno e instalación del complejo industrial se llevó a cabo entre 1931 y 1933 . A pesar de los esfuerzos logísticos y de la celeridad que se trató de dar a las obras hubo que esperar hasta 1935 para el arranque de la azucarera, un proyecto industrial que obedece a la reorganización general del negocio del azúcar en esos años, pues la Santa Elvira se abre tras el cierre de la planta azucarera de La Rasa, en Soria, en el contexto de un proceso de concentración y modernización común a todo el sector.

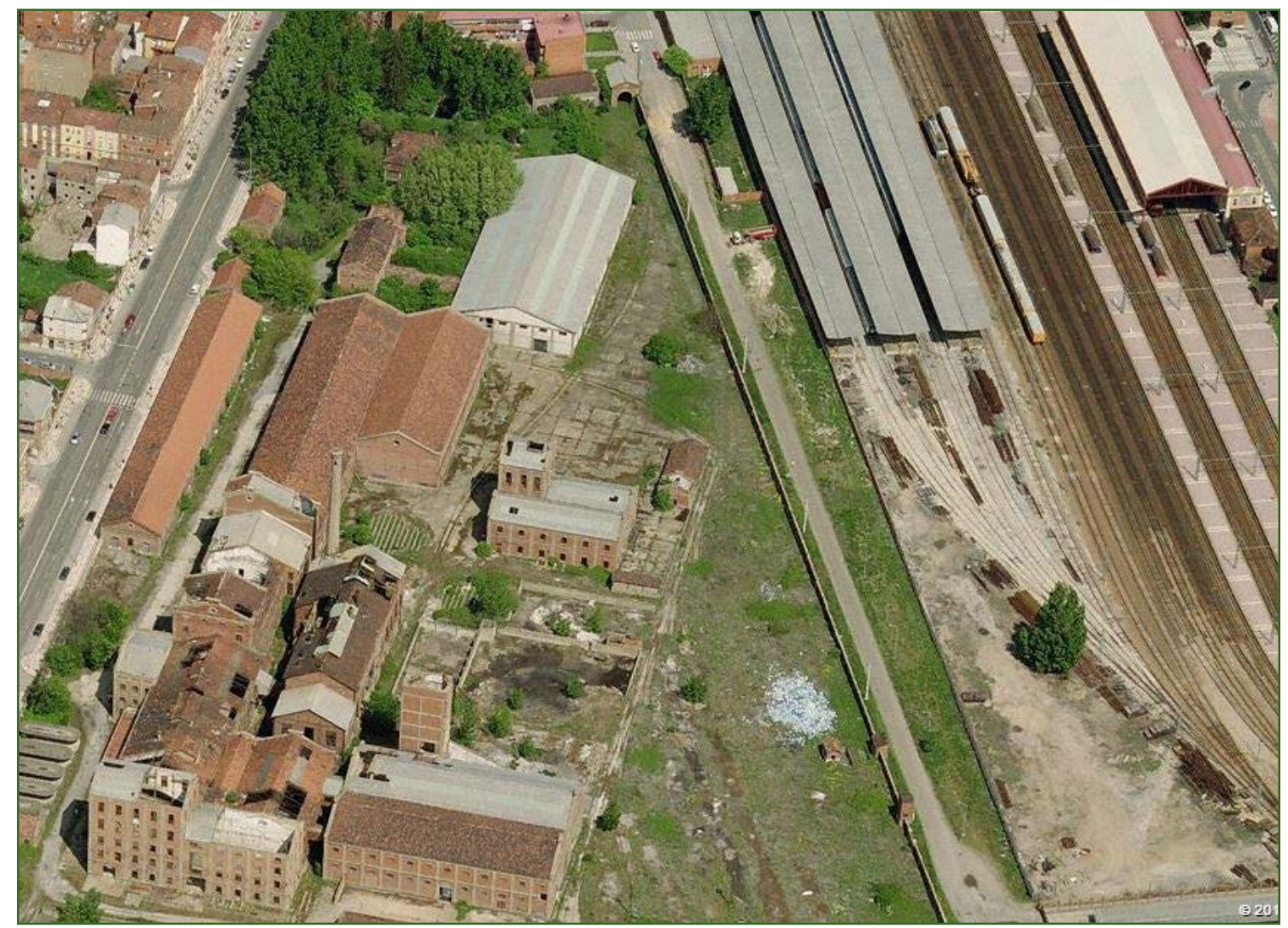

Figura 2. Instalaciones de la azucarera Santa Elvira en las inmediaciones de la parrilla de vías y estación de ferrocarril del Norte

Fuente: Elaboración propia y visor Bing Maps. En amarillo el antiguo trazado de la línea del ferrocarril extendida hasta la azucarera.

Desde el punto de vista del negocio, la azucarera registró una intensidad de producción notable a lo largo de su vida industrial. Inicialmente su capacidad de molturación fue de $700 \mathrm{Tm} /$ día, cifra que fue en aumento sobre todo durante los años 
sesenta y setenta del siglo XX gracias a importantes inversiones de modernización de maquinaria, lo que permitió llegar a producciones de 1.200 Tm/día en 1960; unas 3.000 Tm/día en 1970, hasta un pico máximo de 3.600 Tm/día de producción en los años finales de la fábrica. Por su parte, la mano de obra empleada alcanzó los 200 trabajadores en el año 1980, cifra que se elevaba notablemente durante los períodos de campaña de recogida de la remolacha.

La Santa Elvira tuvo a su vez una cierta capacidad de arrastre sobre las industrias afines, como lo demuestra la instalación en 1945 en sus inmediaciones de una destilería de alcohol (operativa hasta 1980) y otros pequeños negocios que contribuyeron a reforzar el carácter industrial del oeste de León, un sector urbano que consolida su condición de espacio industrial en la segunda mitas del siglo XX y que acumula atributos que permiten asimilarlo al modelo de barrio industrial, que entrará en crisis en los años de 1990. Asimismo, las transformaciones inducidas por el ferrocarril fueron potenciadas por la azucarera, cuya presencia refuerza y consolida el carácter obrero-industrial del sector oeste de la ciudad, favoreciendo la concentración de población en la zona, la expansión del suelo residencial y cierto desarrollo de equipamientos básicos, aunque también se agudiza el efecto barrera del río Bernesga y emergen elementos de marginalidad y factores de degradación medioambiental ligados a la actividad fabril (figura 3).

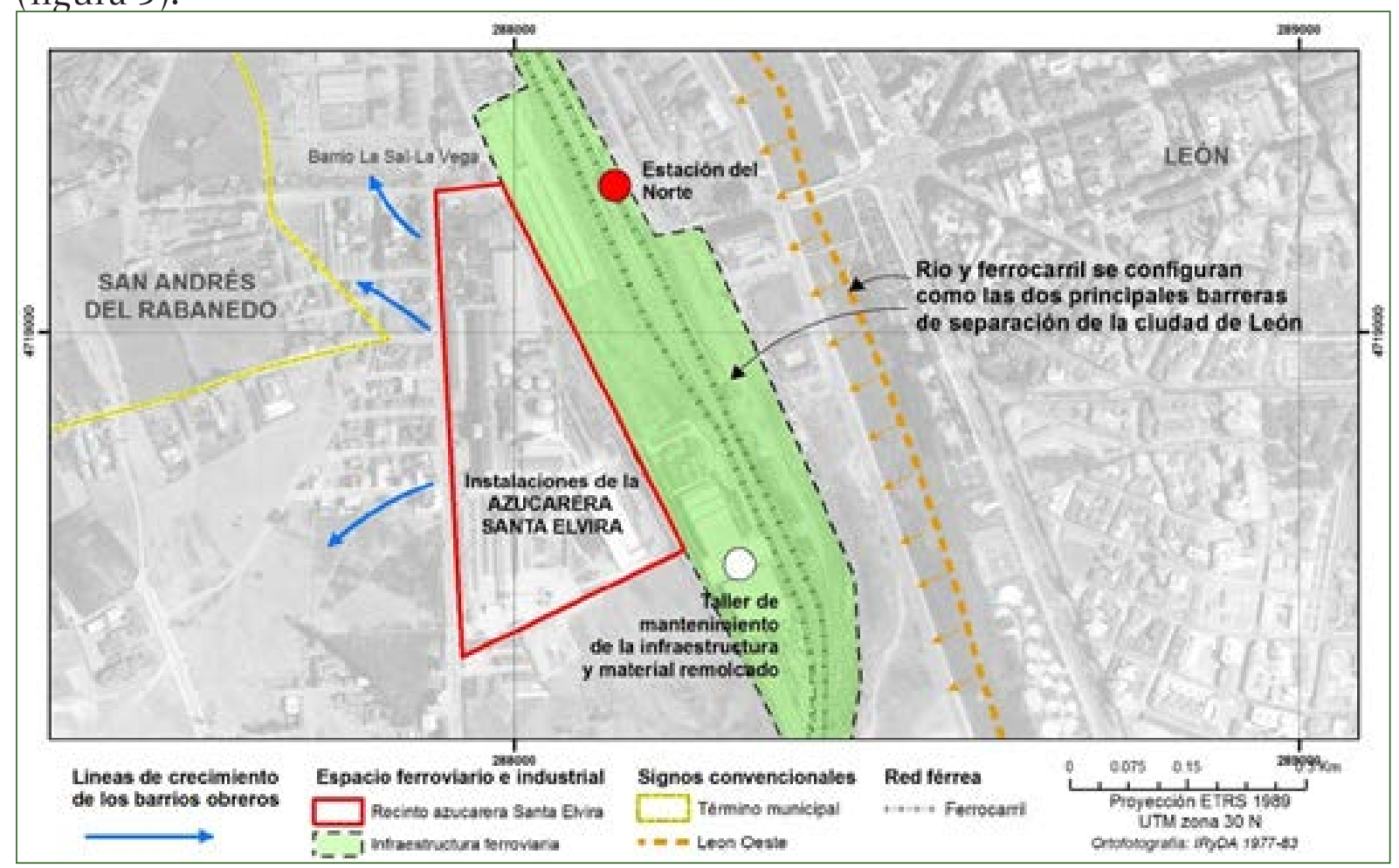

Figura 3. Esquema interpretativo del impacto urbanístico de la azucarera de León . Fuente: Elaboración propia. 


\section{Retos de la desindustrialización: crear nueva ciudad a partir de viejas fábricas}

\section{Declive del azúcar y emergencia de un nuevo desafío: las ruinas de la "Santa Elvira"}

Las nuevas condiciones que se crean para producción de azúcar en España a partir del ingreso en la Comunidad Económica Europea en 1986 desencadenaron un proceso de reestructuración del sector, ampliamente descrito por la literatura económica que tuvo sus efectos en la actividad de la Santa Elvira. Los cambios empezaron en el frente empresarial: la Compañía de Industrias Agrícolas y Ebro Compañía de Azúcares y Alimentación, que en 1967 habían adquirido el 95\% del capital de la Sociedad Industrial Castellana y, en consecuencia, eran dueñas de la Santa Elvira, se unen en 1990 formando Ebro Agrícolas Compañía de Alimentación, S.A.

Poco después de esta fusión, la implantación del llamado Plan 92 (cuyo objetivo principal era tecnificar y modernizar el cultivo de la remolacha) situó en la encrucijada al sector del azúcar y ocasionó el cierre de cinco fábricas. En aplicación del mismo, en septiembre de 1991 se hizo público que la fábrica leonesa, junto a otras tres de Burgos, Vitoria y Badajoz, dejarían de funcionar en razón de una estrategia de concentración que en el caso leonés beneficiaría a la factoría de La Bañeza . En este contexto, el 2 de marzo de 1992 los sindicatos y la empresa Ebro acordaron el cierre total de la Santa Elvira, que contaba entonces con 182 trabajadores fijos y 200 discontinuos, a los que se les aplicaron distintas medidas de ajuste laboral:jubilación anticipada, traslado a otras fábricas del Grupo Ebro o indemnización por despido. El desmantelamiento técnico de la fábrica se concretó en el traslado de la maquinaria aprovechable a las fábricas de Peñafiel (Valladolid) y Miranda de Ebro (Burgos) y la venta como chatarra del resto. Por su parte, los edificios e instalaciones de la factoría fueron cerrados y abandonados, sin apenas repercusión social del hecho y con el resultado de un evidente abandono, estado de ruina y degradación del entorno, lo que reforzó la percepción negativa de la vieja fábrica y enmascaró su valor patrimonial.

Pocodespués del cierreenlaciudad sealzaronalgunasvocesafavordela protección y conservación de la fábrica. Y en este punto se advierte una acción relevante protagonizada por los técnicos municipales que en el año 2000 incluyen los edificios centrales del complejoazucarero en elCatálogo de Bienes y Elementos Protegidos que acompaña al Plan Especial de Protección del Conjunto Urbano de la Ciudad de León. Otro hito a destacar es el Inventario de instalaciones industriales abandonadas, realizado por la Universidad de León en 2002 y que contiene una defensa decidida de la azucarera. Se puede afirmar que ambos documentos marcan un punto de inflexión en el proceso social de toma de conciencia y defensa expresa del patrimonio industrial en León, que hay que vincular a una corriente de opinión extendida por numerosos lugares del país favorable a la defensa y conservación de las viejas fábricas. En 2004 se produce el compromiso institucional más decisivo para al futuro de la 
azucarera: el nuevo Gobierno de la ciudad, en manos de los socialistas, y la propia Junta de Castilla y León se comprometieron a apoyar la conservación del patrimonio industrial, dando con ello desarrollo formal a lo expresado en el denominado Plan PAHIS (2004-2012) del Patrimonio Histórico de Castilla y León con medidas concretas sobre protección y conservación del patrimonio industrial. En tal contexto, el Ayuntamiento de León suscribió un convenio con fecha 12 de mayo de 2004 con la entidad Ebro Puleva, SA, propietaria única de los terrenos e instalaciones de la azucarera Santa Elvira, para adquirir el conjunto fabril como dotación urbanística pública al servicio de todo el municipio. En dicho convenio se llegó a tres compromisos que afectan a las instalaciones de la azucarera y su entorno:

-Desarrollo urbanístico del área circundante a la instalación industrial (en el que se contempla la construcción de 600 viviendas) respetando la fábrica de azúcar en su totalidad.

-Asignación a la antigua Azucarera Santa Elvira de un nuevo uso, con el que se pretende que el antiguo recinto industrial dé servicio como futuro Palacio de Congresos y Exposiciones y como Recinto Ferial.

-Diseño de la futura integración del ferrocarril.

Con este convenio el Ayuntamiento desbloquea la parálisis de los terrenos de la azucarera, da satisfacción al sector inmobiliario y financiero y crea un foco de interés inversor sobre una zona degradada que puede llegar a convertirse en un polo de centralidad, con el componente añadido de que respetando la azucarera las instituciones locales se ponen en sintonía con la creciente corriente social de defensa del patrimonio industrial, aunque esto será un espejismo transitorio, pues la realidad mostrará una intervención que mutila la fábrica y solo respeta la apariencia de una parte del conjunto industrial, una acción a caballo entre la reutilización adaptativa y la destrucción del patrimonio vinculada a estrategias de recalificación de suelo apreciadas en multitud de espacios urbano-industriales históricos, según apuntan algunos autores.

\section{Primeras iniciativas e instrumentos para la renovación del sector oes- te de León}

Los responsables municipales, antes y después de asumir el discurso de conservación de la vieja fábrica de azúcar y proyectar una intervención de gran alcance sobre sus terrenos y edificios, pusieron en marcha iniciativas orientadas a mejorar las condiciones de los barrios del oeste de León, habida cuenta de la desindustrialización de amplios espacios y la deficiente dotación de servicios e infraestructuras que lastraban la zona, donde eran factibles nuevos desarrollos de suelo residencial y dotación de equipamientos que pudieran dar un aire de modernidad a la ciudad, en consonancia con lo que se estaba planificando y ejecutando en otras ciudades 
medias de similar trayectoria. En esta línea destacan dos iniciativas: el Proyecto Urban León Oeste 1997-2002 y el Plan General de Ordenación Urbana aprobado en 2004 y vigente en la actualidad.

\section{Proyecto Urban León Oeste 1997-2002}

Se enmarca en un ambicioso programa de financiación europea (fondos FEDER y FSE) y su objetivo es reestructurar y recualificar los barrios industriales del oeste de León, una zona estrangulada en su crecimiento por el ferrocarril, con un tejido urbano muy degradado, viviendas en malas condiciones y falta de equipamientos sociales y dotaciones en general, y con una población de 15.305 habitantes (el 10.6\% de la población de la ciudad). Con un enfoque integrado de rehabilitación socioeconómica y urbana, el Proyecto Urban pone el foco en tres aspectos: a) el factor medioambiental; b) el desempleo de larga duración; y c) la igualdad hombre/mujer. El ámbito de actuación o límite de la zona beneficiada queda definido de la siguiente forma: al norte, por la línea de separación entre el término municipal de León y el de San Andrés del Rabanedo; al oeste, por la línea que separa los municipios de León y Oteruelo; al sur, hasta la Ronda de circunvalación (N-120); y al este, el límite de actuación va paralelo a las vías ferroviarias que discurren junto al río Bernesga).

Aquí se detectan los problemas clave: barreras urbanísticas, altos niveles de desempleo femenino y juvenil, dinámicas demográficas de riesgo (fuerte envejecimiento), equipamientos y servicios sociales deficientes y escasos, y arraigo de actividades marginales por parte de minorías étnicas. Las actuaciones se llevaron a cabo durante los cinco años de vigencia del Proyecto y los fondos, un total de 10 millones de euros (aportados en un 70\% por la UE a través del FEDER y el FSE), se aplicaron a la creación de nuevos equipamientos culturales, sociales y centros cívicos, se activaron programas de promoción de empresas y de formación para el empleo, y se construyó un nuevo puente sobre el Bernesga. En suma, un conjunto de acciones que permitieron mejorar las condiciones de partida de los barrios afectados y que representan el germen de posteriores políticas del Ayuntamiento de León en materia de empleo, formación y nuevas tecnologías. Este Proyecto será asimismo el punto de partida de otro instrumento de la política urbanística sobre el mismo sector de la ciudad: el ARI-Área de Rehabilitación Integrada León Oeste, que actualmente se encuentra en fase de ejecución. Se puede afirmar, pues, que el Proyecto Urban fue el detonante del proceso de renovación en el que actualmente está inmerso el oeste de León (figura 4).

\section{Plan General de Ordenación Urbana (PGOU) 2004}

Este instrumento marca las líneas de actuación de la política urbanística desde el año 2004 hasta el presente, haciendo hincapié en la integración del ferrocarril, la rehabilitación de viviendas y la preparación y transformación de los terrenos y edificios de la azucarera en un gran equipamiento público. La integración del 
sistema ferroviario de Renfe, con acciones como la eliminación y/o soterramiento de las históricas vías de hierro que dividen los barrios industriales, la supresión en este ámbito de los tráficos de mercancías y la construcción de una nueva estación de viajeros, conforman la principal propuesta estratégica que afecta de lleno al sector Oeste.

Con ella se pretende favorecer la circulación ferroviaria en sentido Norte-Sur, eje que conecta la ciudad con el exterior, eliminar barreras urbanas obsoletas para crear espacios de circulación y relación más eficientes, abrir nuevas vías de conexión entre ambas márgenes del río, comunicando la ciudad consolidada con la "nueva ciudad en construcción", y reforzar la intermodalidad, al reubicar la estación de Renfe y unirla mediante un intercambiador a la estación de autobuses. Respecto a la rehabilitación de viviendas, se plantea la mejora del estado de las viviendas de los barrios obreros cercanos a la estación de trenes y a la vieja fábrica azucarera.

La propia integración del ferrocarril conlleva la mejora de las medianeras y edificios colindantes al pasillo de vías. Las labores de rehabilitación y mejora de viviendas e infraestructuras se extienden más allá de los caminos de hierro. De esta forma, la planificación de nuevos viales y edificaciones, así como la mejora estructural y estética de muchos de ellos se generaliza en este sector, cobrando un especial protagonismo en los barrios de Pinilla y Quevedo, en la Armunia y en Trobajo del Cerecedo (figura 4). Por último, entre las propuestas del PGOU 2004 destaca la transformación de la azucarera en un gran equipamiento público concebido como símbolo de la nueva imagen que se desea proyectar de la ciudad: el Palacio de Congresos y Exposiciones. En efecto, como intervención complementaria al proyecto de integración del ferrocarril el PGOU plantea ordenar e incorporar al desarrollo urbanístico de los antiguos terrenos ocupados por la azucarera (calificados como Suelo Urbano No Consolidado), expresivos de un fenómeno de "baldío industrial" asociado a la degradación ambiental y física del entorno. Todo ello, en principio, respetando y cumpliendo con la conservación del complejo azucarero y con su integración en el Sistema General de Equipamientos (figura 4).

\section{Acciones estratégicas para la renovación del León Oeste}

\section{Construcción del Palacio de Congresos y Exposiciones a partir de la vieja azucarera}

Como se ha señalado más arriba, la intervención en el recinto y los edificios de la azucarera representan la acción más rotunda y emblemática en los barrios que se articulan en torno al ferrocarril. Sin duda el Ayuntamiento jugó sus bazas con habilidad y apostó, en un momento en que la Junta se disponía a aprobar el Plan PAHÍS de Patrimonio Artístico e Histórico regional, por una solución que respetaba los edificios más representativos de la vieja azucarera y la salvaba de la destrucción, aunque se tratará de una rehabilitación selectiva pues conlleva la destrucción de 
la mayoría de los edificios del recinto heredado. Esta postura oficial de aparente respeto al patrimonio industrial sintoniza, como se ha dicho, con la corriente de opinión local favorable a conservar la vieja azucarera. Pero ante todo responde a una política municipal oportunista, que va a permitir acometer una renovación urbana de gran alcance aprovechando los fondos públicos que el Gobierno de España y el Gobierno regional destinan a la recuperación del patrimonio cultural. Los pasos que permitirán al Ayuntamiento de León materializar esta acción de renovación urbana centrada en la rehabilitación de la azucarera se resumen en: primero, convocar en 2005 un concurso internacional de ideas para diseñar el Palacio de Congresos y Exposiciones, que se resuelve a favor del proyecto que presenta el francés Dominique Perrault; segundo, adjudicar en 2007 el Proyecto Básico, de Ejecución y Dirección de las Obras a la firma de arquitectura Dominique Perrault Architecture SARL (DPA); y tercero, firmar acuerdos de financiación con los otros dos grandes agentes de esta operación urbanística, el Ministerio de Industria, Comercio y Turismo y la Junta de Castilla y León. Los principales compromisos serán, según consta en la Memoria 2010 de la sociedad gestora del proyecto, los siguientes:

Con fecha 30 de noviembre de 2009 el Ministro de Industria, Comercio y Turismo y el Alcalde de León firmaron el Convenio de Financiación para hacer efectiva la subvención del Ministerio correspondiente a la anualidad 2009 para el impulso de la construcción del nuevo Palacio de Congresos y Exposiciones por un importe de 1.500 .000 de euros.

El día 30 de noviembre de 2009 los mismos agentes firmaron el Convenio-Marco de financiación plurianual para la construcción del Palacio de Congresos y Exposiciones de León. Aquí se recogen las subvenciones del Ministerio correspondientes a las anualidades 2010,2011 y 2012 con unas cantidades de seis, ocho y 9,98 millones de euros respectivamente.

El 7 de diciembre de 2009 se firma el Convenio Marco que establece el compromiso de la Junta de Castilla y León de subvencionar el proyecto con una cantidad total de 30.488.477 euros en el período 2009-2013.

Con fecha 11 de diciembre de 2009 se adjudicaron inicialmente de obras del "proyecto de construcción y rehabilitación del Palacio de Congresos y Exposiciones de León, fase 2. Pabellón de usos complementarios (Petit Palais). Importe total de 2.210.042,12 euros. Las obras finalizaron el 24 de marzo de 2011. La explotación y utilización de este edificio ya ha comenzado.

Con respecto al proyecto en ejecución, la intervención en la azucarera y su entorno, consiste, al decir de su promotor, en la adaptación de la antigua fábrica en lugar de encuentro social y cultural, es decir, una antigua refinería que se convierte en Palacio de Congresos y en Recinto Ferial como parte de una operación de reordenación del sector oeste de León motivada por la llegada del tren de alta velocidad. El edificio resultante incorpora acciones medioambientales como es una gran cubierta 
fotovoltaica translucida que servirá de protección solar al interior del recinto ferial y lo abastecerá de energía eléctrica.

Figura 4.Principales actuaciones de regeneración urbana en el sector oeste de León desde 1997

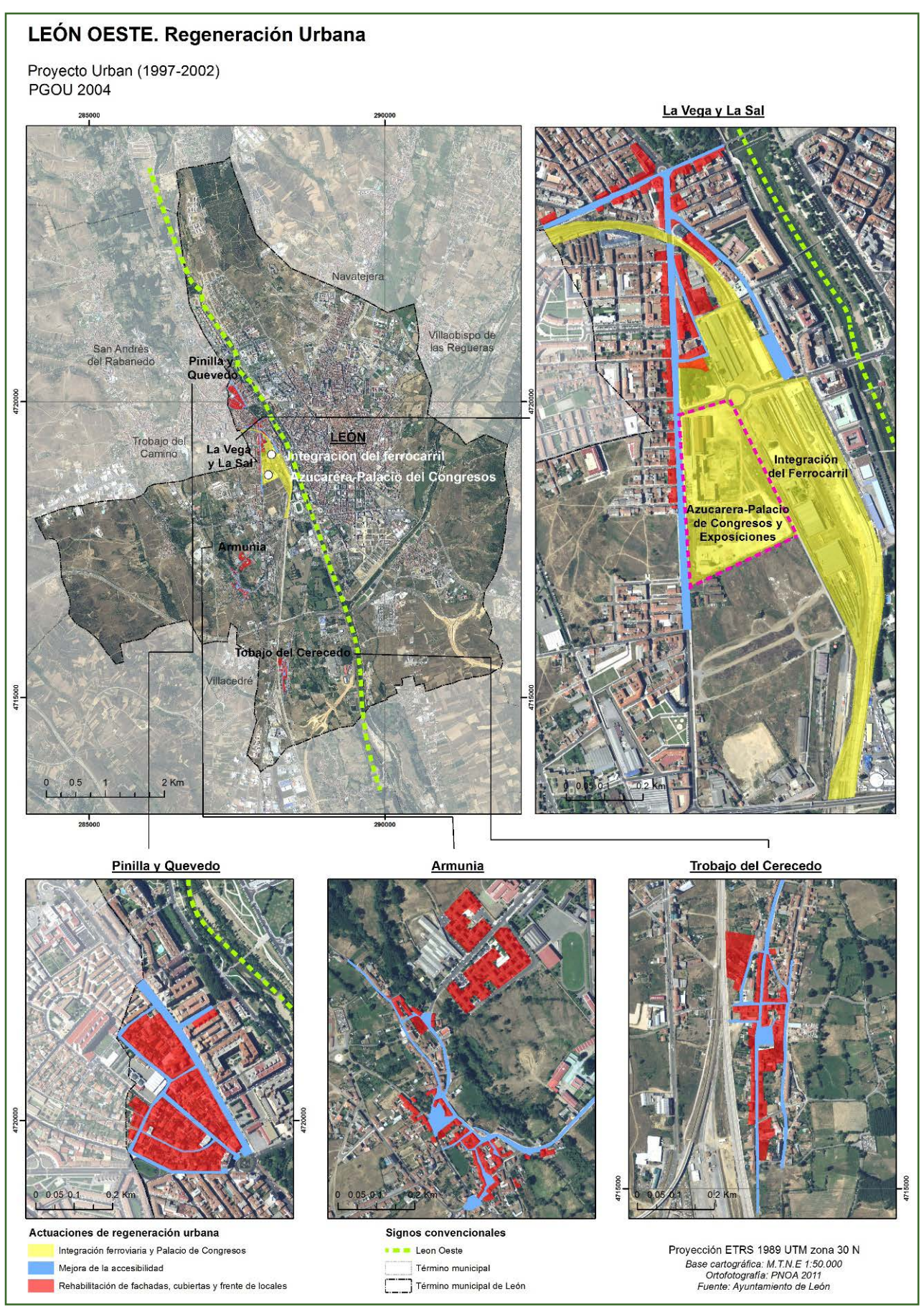

hasta la actualidad

Fuente: Elaboración propia.

El edificio con uso de Recinto Ferial tiene una superficie de $12.700 \mathrm{~m}^{2}$ y dispondrá de tres grandes salas de nueva construcción; el Palacio de Congresos, ubicado 
sobre los edificios existentes de la antigua azucarera, estará dotado de auditorio, salas de conferencias, de reuniones, de exposiciones, aulas, etcétera. Y como programa anexo se propone un edificio de usos complementarios, con oficinas de gestión, salas polivalentes y cafetería-restaurante, con una pequeña plaza asociada para actividades al exterior. Entre el Palacio y la zona de la nueva estación provisional de ferrocarril se planifica una gran plaza, con zona de aparcamiento (figura 5).

Hasta el momento presente el proyecto de rehabilitación de la azucarera está parcialmente ejecutado (finalizado el edificio de usos complementarios, denominado Petit Palais) aunque las obras del Palacio de Congresos, llamado Grand Palais, también objeto de acciones de rehabilitación, van con retraso y están sin concluir, al igual que el Palacio de Exposiciones, de nueva planta (figura 6).
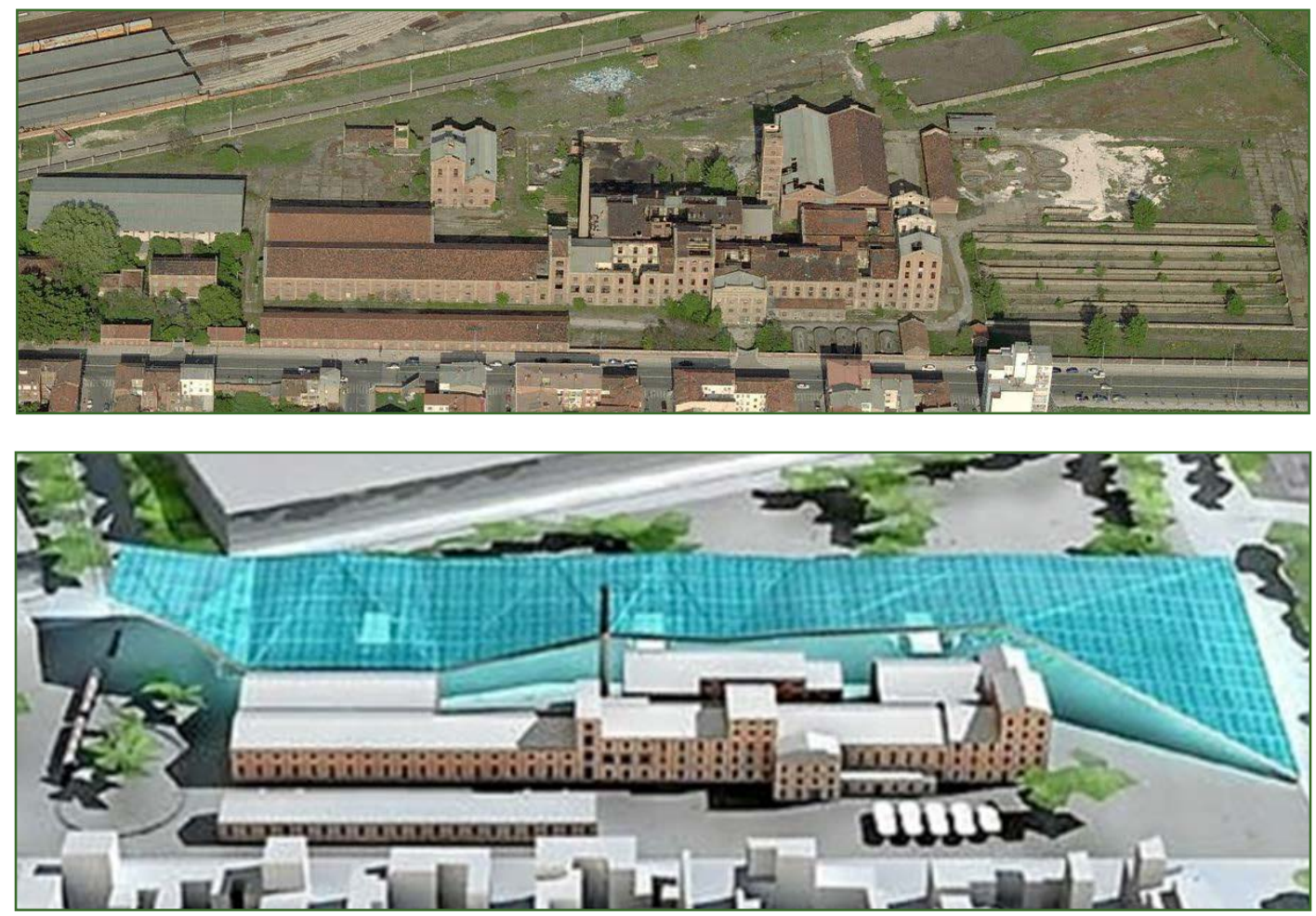

Figura 5. Recinto original de la azucarera y resultado de la intervención de rehabilitación y cambio de uso de las naves industriales según el proyecto de Perrault

Fuente: Elaboración propia a partir del Visor Bing Maps y de www.elmundo.es 


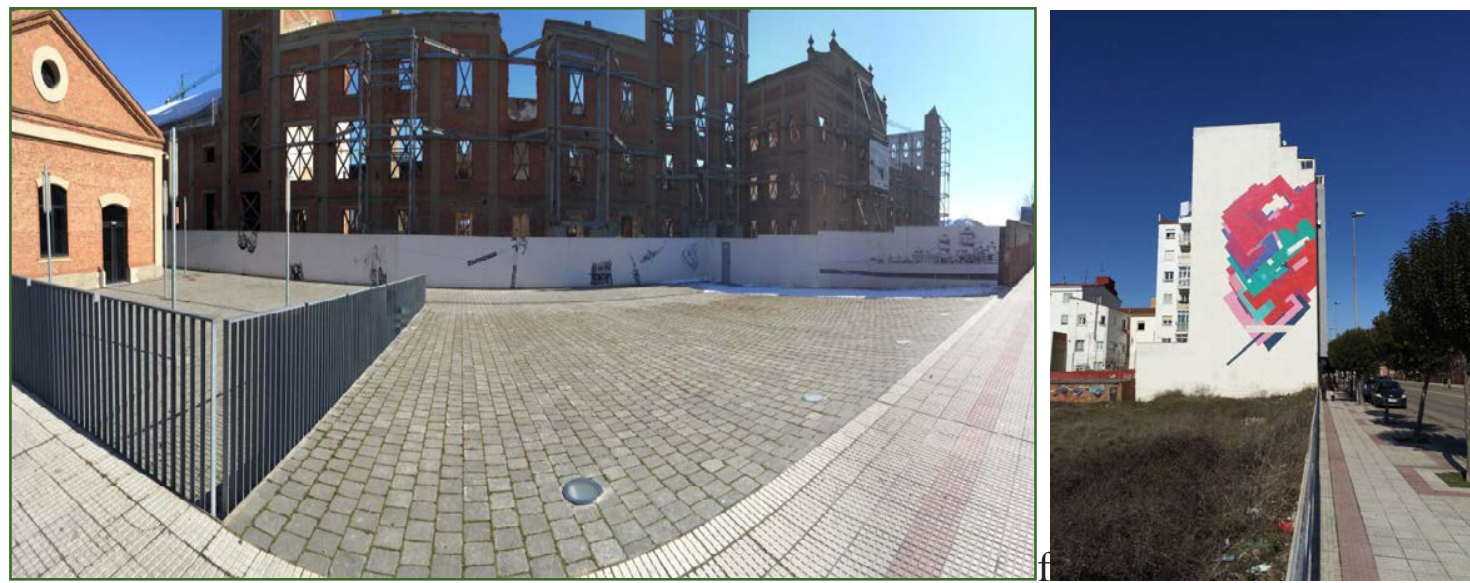

Figura 6.

Fuente: Imágenes de los autores tomadas en 2015.

\section{Alcance de la integración del ferrocarril y apuesta por el tren de alta velocidad}

En su entorno se ha trazado un nuevo eje viario, prolongación de las calles Ordoño II y Palencia hasta su entronque con la avenida Doctor Fleming, se ha clausurado la estación de trenes histórica y desactivado su parrilla de vías para proceder al soterramiento del ferrocarril, y a escasos metros de ella se ha construido una nueva, que no se ajusta al proyecto de Perrault porque era una solución provisional, pero la falta de presupuesto la convierte en una alternativa definitiva, es decir, en la actual y permanente estación a la que llega desde octubre de 2015 el tren AVE que conecta León con Madrid,y en un futuro está previsto que llegue hasta Asturias.

La importancia estratégica del ferrocarril en León es reconocida en el propio PGOU de 2004, tanto para articular el espacio provincial dentro del cuadrante noroccidental de la península como para favorecer el transporte metropolitano. Existen dos estaciones de ferrocarril diferentes: la estación del ferrocarril del Norte, ubicada en el barrio del Crucero y gestionada por Renfe-Adif, que mantiene las líneas con Vigo, La Coruña, Madrid, Gijón, Barcelona y Alicante. Y la estación de Matallana de Feve situada en la Avenida Padre Isla, en el centro de la ciudad, con vocación metropolitana y punto de partida del Transcantábrico y de numerosos trenes regionales a Bilbao. Los estrangulamientos urbanísticos y las ineficiencias generadas por estos trazados ferroviarios, en buena parte obsoletos e incompatibles con el modelo de ciudad que a principios del nuevo milenio se debate para León, se tratan de solucionar con la firma de un documento estratégico que debe, asimismo, responder a otro desafío inminente: la llegada de la alta velocidad. En consecuencia, en 2002 se firma el "Convenio para la Integración ferroviaria en León y San Andrés del Rabanedo" entre el Ministerio de Fomento, la Junta de Castilla y León, el Ayuntamiento de León y el Ayuntamiento de San Andrés del Rabanedo que incluye las acciones que se detallan en el cuadro 1 y se reflejan en la figura 7. 


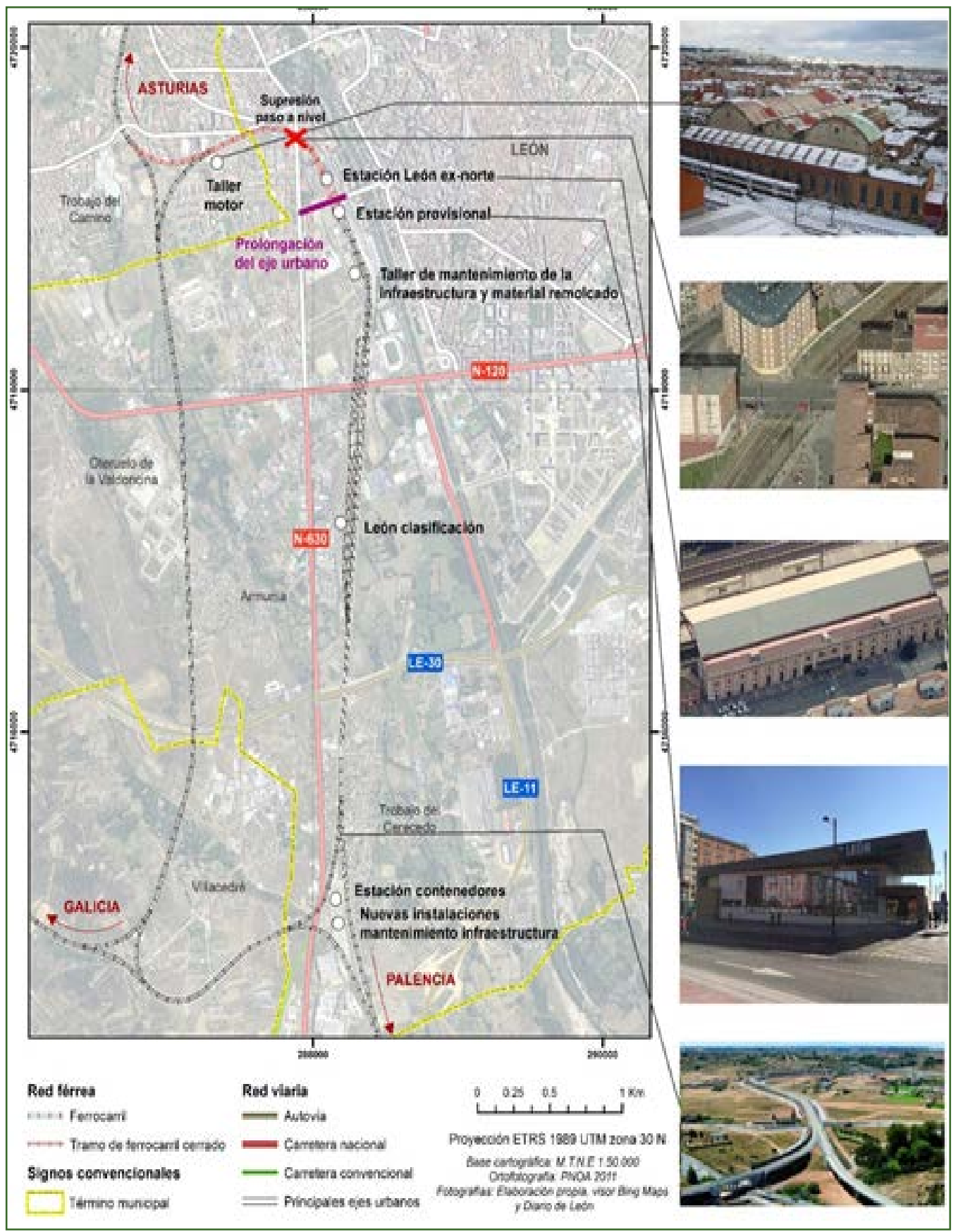

Figura 7. Representación de las primeras acciones de integración del ferrocarril en León y su impacto en la reordenación de la ciudad y su alfoz

Fuente: Elaboración propia.

Modificación de la rasante ferroviaria, deprimiendo el nuevo haz de vías de la Estación del Norte, para facilitar la permeabilización de la travesía.

Soterramiento del eje ferroviario en el sector coincidente con la avenida Doctor Fleming, para suprimir el paso a nivel y facilitar la conexión de la trama urbana aislada del sector oeste con el resto de la ciudad. 
Creación de una nueva estación de viajeros localizada a nivel superficial junto a las vías férreas operativas.

Permeabilización de la nueva travesía mediante nuevos pasos rodados y peatonales y reordenación del viario en el entorno de la Estación del Norte clausurada.

Traslado de los Talleres de Material Motor y Remolcado, así como de las instalaciones de Mantenimiento de Infraestructura, a nuevos emplazamientos (Torneros) y eliminación de las instalaciones en desuso.

Racionalización de los recintos ferroviarios de clasificación y de la Terminal de Contendedores situada en Torneros.

Diseño y construcción del enlace ferroviario sur sobre las vías del eje Palencia-Monforte $(5,9 \mathrm{~km})$ para facilitar la ejecución de las obras en las inmediaciones de la Estación del Norte. También servirá para suprimir el paso por el centro urbano de las principales conexiones ferroviarias entre Galicia y Asturias con el centro peninsular, que no requieran parada en León.

Profundización más severa del haz de vías de la futura estación de ferrocarril, para dar continuidad al eje urbano Ordoño II-calle Palencia y mejorar la ordenación urbanística en la zona.

Soterramiento de 2.700 metros de vías de ferrocarril en los núcleos urbanos, para facilitar la continuidad de las avenidas que tienen sentido transversal a la estación.

Cuadro 1. Acciones incluidas en Convenio para la Integración ferroviaria en León y San Andrés del Rabanedo, 2002

Fuente: Elaboración propia.

Para el logro de los objetivos apuntados en el cuadro 1 en el año 2006 se planteó un concurso internacional denominado "Concurso-plan regional de ámbito territorial para la planificación de las actuaciones urbanísticas derivadas de la implantación de las nuevas infraestructuras y equipamientos ferroviarios en León, San Andrés del Rabanedo, Onzonilla y Santovenia de la Valdoncina", al que se presentaron seis candidaturas diferentes, ganando la propuesta denominada Desde Lancia, que plantea la consecución de todos los objetivos de mejora en el ámbito ferroviario establecidos en el convenio de 2002. Como primer hito de la transformación propuesta (y como intento de racionalizar la circulación de trenes en el centro urbano) se construyó en 2008 un nuevo enlace ferroviario para mercancías en Onzonilla, el llamado Enlace Sur (Figura 7 ), que permite disociar el trasporte de viajeros y de mercancías y hace posible las obras de la estación provisional de Renfe, diseñada en fondo de saco (ausencia de continuidad del trazado férreo por el casco urbano, lo que implica un desplazamiento marcha atrás de los trenes hasta el referido Enlace Sur, donde retoman la circulación normal). 
La idea inicial era que dicha estación fuera de uso provisional, mientras se llevaban a cabo las obras de soterramiento de vías y se construía la estación del Tren de Alta Velocidad. La Figura 8 ilustra los cambios descritos y el nuevo paisaje que se perfila desde la glorieta habilitada para articular el eje viario que enlaza Ordoño II y Doctor Fleming, determinante de la nueva centralidad del León Oeste, reforzada tras la reciente entrada en servicio de la línea de Alta Velocidad Palencia-León.

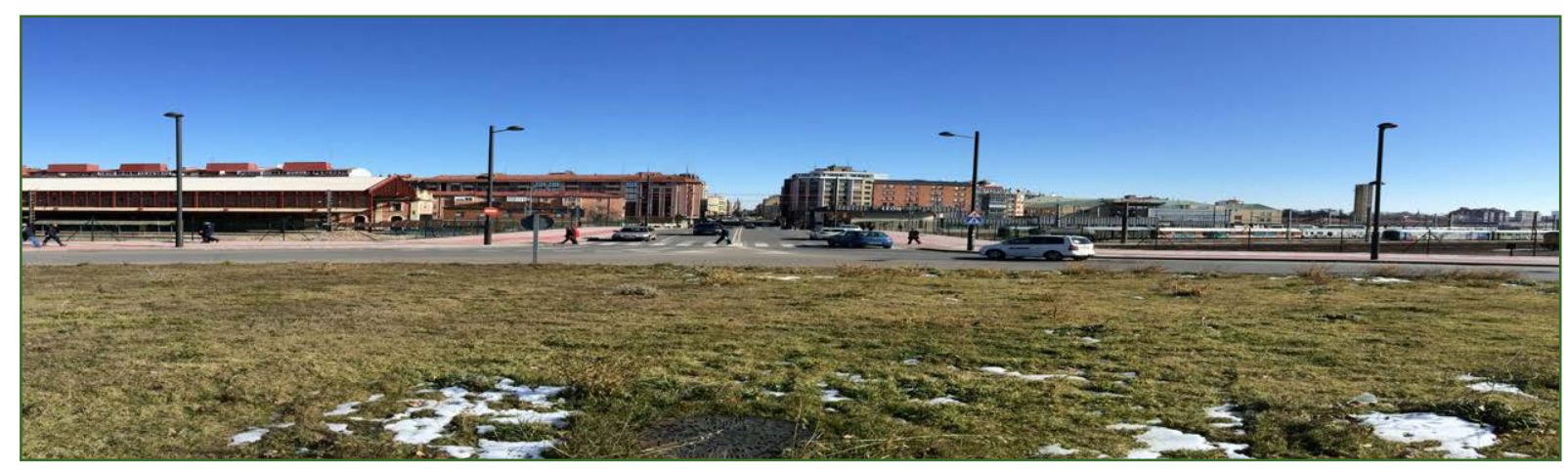

Figura 8. Paisaje resultante de las acciones de renovación en la zona ferroviaria de León

Fuente: Elaboración propia. Se prolonga el eje Ordoño Il-calle Palencia sobre el río Bernesga hacia Doctor Fleming y Palacio de Congresos, con presencia de la Estación del Norte abandonada y nueva estación de trenes para viajeros de Adif

Las intervenciones que se acaban de señalar conllevan no solo alteraciones importantes de la trama urbana, sino también cambios notables en la movilidad, con el resultado de la desaparición de los atascos de tráfico y las largas colas de espera debidas al paso a nivel de El Crucero o de los rodeos para desplazarse entre puntos relativamente cercanos, pero poco accesibles de un lado y otro del río a la altura del centro. La figura 9 muestra el impacto de las mejoras y los cambios en los desplazamientos, tomando como referencia una ruta cotidiana de tráfico rodado entre la céntrica plaza de Santo Domingo y los barrios del oeste, con el resultado de una movilidad más eficiente que cabe interpretar como un avance en la mejora de las condiciones de habitabilidad y accesibilidad del León renovado y como una mejora de la conexión entre el espacio central y los barrios antaño marginados.

Por su parte, la solución al fondo de saco ferroviario de León se acompaña de la necesaria acción de soterrar 600 metros de longitud de vías entre la estación provisional de Adif y la zona en la que estaba el paso a nivel de El Crucero, suprimido como se sabe en 2011. En un replanteamiento del proyecto de 2006 se ha descartado, por falta de presupuesto, el soterramiento integral del ferrocarril a su paso por León y parte del municipio de San Andrés del Rabanedo (Figura 10) al tiempo que se propone la recuperación de la traza ferroviaria y de la vieja Estación del Norte, para la que se baraja un uso hotelero, toda vez que el gran hotel de lujo que acompañaba al proyecto original del arquitecto Perrault está definitivamente descartado. En esta revisión oficial de las acciones previstas, la estación provisional de Adif será ampliada unos 450 metros y quedará consagrada como la definitiva Estación de Ferrocarril de Alta Velocidad de León. 


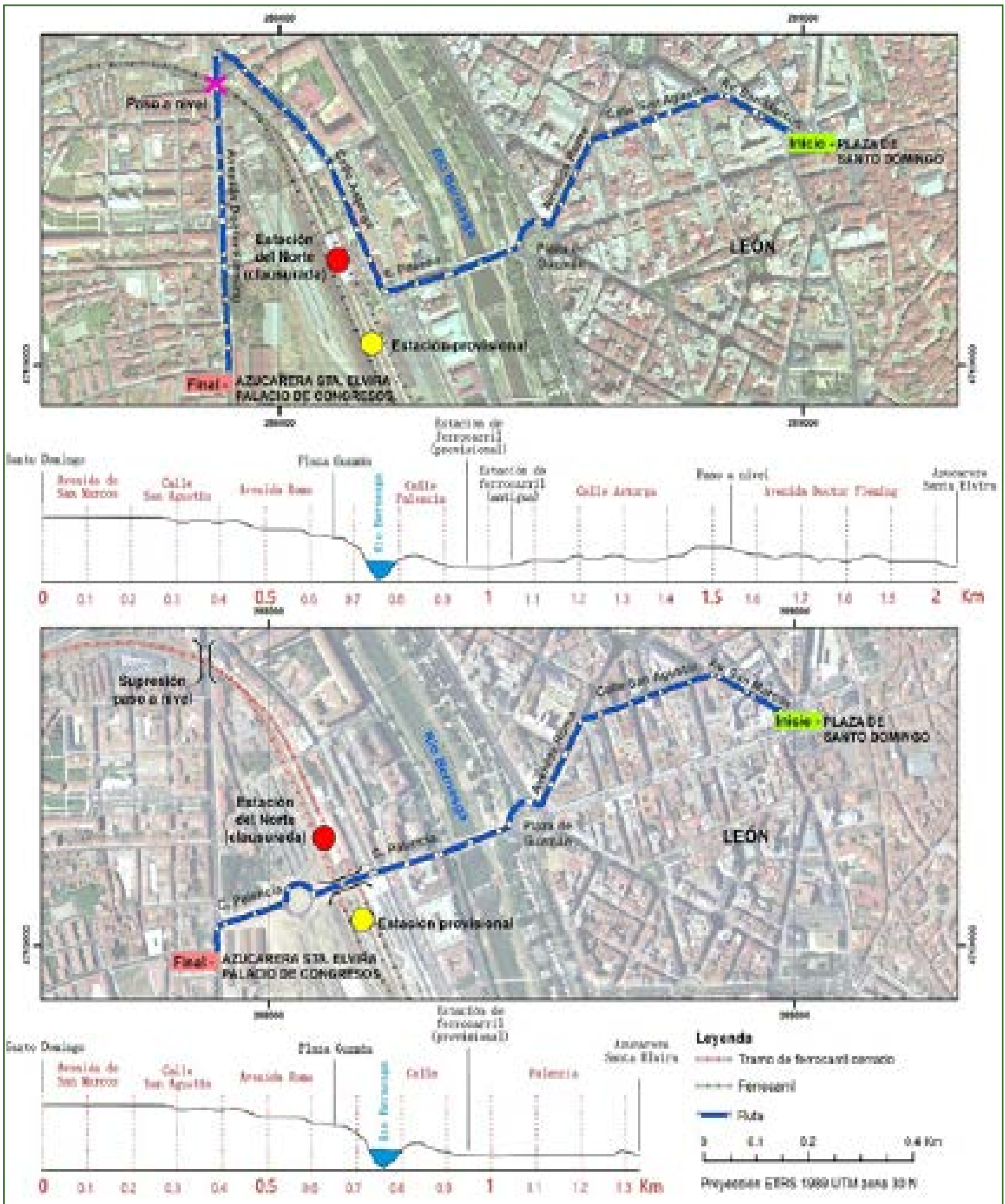

Figura 9.Análisis gráfico de los cambios en la ruta de tráfico rodado entre la plaza de Santo Domingo y la antigua azucarera Santa Elvira de León

Fuente: Elaboración propia. Arriba trazado anterior y abajo trazado posterior a la intervención. 


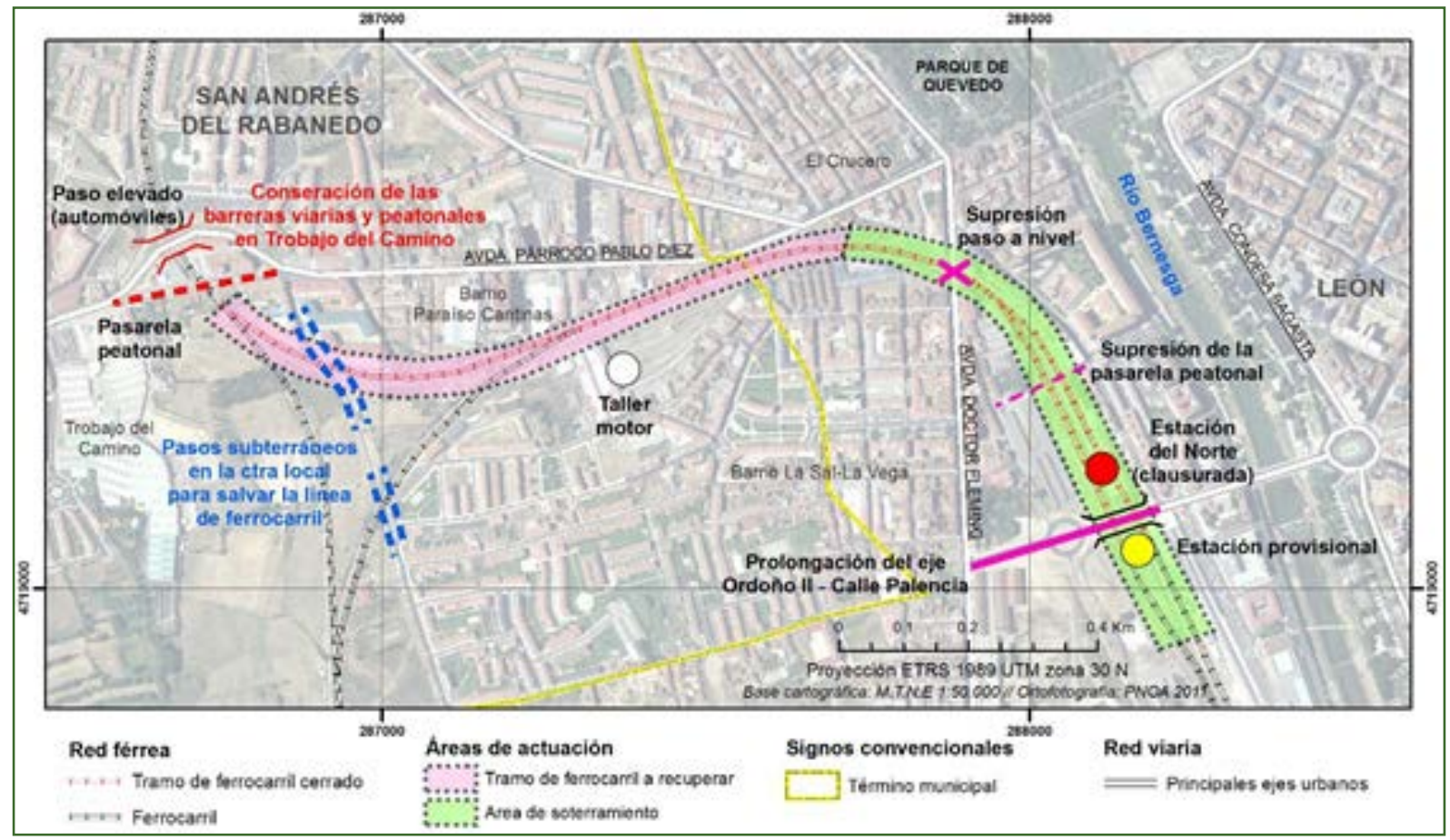

Figura 10. Extensión del plan de intervención ferroviaria desde León hacia el municipio vecino de San Andrés del Rabanedo

Fuente: Elaboración propia.

\section{Conclusiones}

La transformación reciente de los barrios heredados de la industrialización histórica se enmarca en el proceso general de renovación que se aprecia en la mayoría de las ciudades medias españolas, al socaire de una estrategia de política urbana que tiene diversos frentes convergentes: uno, generar espacios residenciales de calidad ocupando los terrenos abandonados por la industria y las infraestructuras ferroviarias obsoletas; dos, dotar a la ciudad de equipamientos terciarios que irradien una imagen de modernidad que se asocia a vistosos edificios con diseño de vanguardia, producto de la rehabilitación o de nuevo cuño; tres, posicionar la ciudad con ventaja en la red de transportes de más alta capacidad y proyección nacional/internacional, lo que incluye el tren de alta velocidad; y cuatro, impulsar funciones que cualifican y mejoran la competitividad en un entorno metropolitano que supone un desafío constante.

La ciudad se configura así en escenario privilegiado de acciones que denotan su condición de recurso en sí mismo, de pieza clave en un contexto territorial dominado por la lógica del capitalismo global, donde se superponen y entrecruzan discursos de gobernanza a veces antagónicos, y donde las crisis se ceban con facilidad porque el afán de negocio prevalece sobre los intereses no lucrativos. En realidad, pese a los cambios y transformaciones que animan la dinámica urbana sigue conservándose la esencia de la ciudad capitalista, pero con morfologías y funciones diferentes.La 
política urbana analizada a través del caso de León trasluce, a su vez, un fenómeno relevante desde el punto de vista de la geografía urbana y es la especialización de las áreas de nueva centralidad en actividades productivas con una clara orientación hacia el turismo urbano (turismo de congresos, turismo cultural...) y en concentrar parte de la oferta de usos residenciales de alta calidad.

El proceso tiene efectos positivos, pues difunde hacia barrios marginales y desatendidos acciones de mejora (mejoras de tipo dotacional, ambiental, de movilidad y accesibilidad) y libera de presión las áreas centrales consolidadas, saturadas y sin lugar para la expansión de usos alternativos ni condiciones para asumir nuevas funciones. Pero también provoca la gentrificación, un fenómeno que favorece a los grupos sociales acomodados, que se instalan en los barrios antes degradados y de ocupación obrera y ahora renovados y con viviendas de alta calidad, desplazando a sus anteriores ocupantes, personas con menos recursos que deben buscar acomodo en zonas con menor presión y viviendas más baratas, un flujo de doble sentido que alimenta la expansión de las periferias a la vez que sostiene la renovación de las áreas centrales y que supone una verdadera transformación del tejido social de los barrios afectados.

Las intervenciones analizadas en el sector oeste de León son asimismo elocuentes de un juego de intereses, relativamente velado, que expresa las tensiones entre el negocio y el interés general: la costosa rehabilitación de la azucarera y la renovación urbanística de su entorno se programan sin una justificación clara de la viabilidad del Palacio de Congresos y Exposiciones, ni de los desarrollos residenciales que completan el proyecto de León Oeste, un ejemplo palmario de operación especulativa que pone en entredicho el acertado proceder de los responsables públicos y los principios de la gobernanza urbana. Por su parte, la necesaria integración ferroviaria se ejecuta a medias, pues la falta de previsión y miope gestión de la crisis económica sobrevenida en 2008 obligan a recortar acciones (menos metros de vías soterradas, estación provisional que se convierte en definitiva, espacio intermodal que se elimina) o a buscar soluciones de urgencia: el hotel de lujo del proyecto original de Perrault se descarta y en su lugar se improvisa el uso alternativo de la antigua estación del Norte para ese mismo fin, sin mediar el deseable estudio sobre la capacidad hotelera de la ciudad ni otros usos posibles para el edificio ferroviario. El análisis empírico pone, además de relieve, que la réplica de modelos como Bilbao no implica el éxito mecánico de la intervención en términos de rentas para la ciudad y ventajas para los ciudadanos.

Es fundamental una gestión honesta y comprometida de los proyectos, que deben acomodarse a la escala económica y de influencia de la ciudad, además de tener la suficiente flexibilidad como para acomodar las intervenciones a coyunturas de crisis sobrevenidas, sin que por ello resulte un fiasco urbanístico. En otro orden, resulta un factor de oportunidad para la ciudad la ejecución de los proyectos de integración ferroviaria, sustentados en un discurso local basado en objetivos de política metropolitana y regional, como se desprende del diagnóstico 
que acompaña al Plan General de Ordenación Urbana y de algunas intervenciones de alcance supramunicipal. Como se ha tratado de demostrar, las intervenciones sobre el ferrocarril no consisten en un mero traslado de ciertos tráficos (mercancías) y actividades y talleres ferroviarios que sobrecargan la ciudad hacia lugares menos molestos; ni la oferta de la alta velocidad para viajeros es una acción desconectada del resto, sino que obedecen unas y otras a la decisión estratégica y concertada de reubicación de funciones para reforzar la posición de León en la logística del norte peninsular, lo que requiere desligar mercancías y pasajeros y crear infraestructuras ferroviarias en un área eficiente y bien dotada, de localización extraurbana como es Torneros, al sur de León.

Queda por dilucidar si la capacidad de negociación de los agentes públicos es suficiente para alcanzar un acuerdo con las autoridades europeas que permita a León configurarse como plataforma logística y centro ferroviario peninsular, dentro del gran eje europeo del Atlántico. En este aspecto la gobernanza es clave para explicar el éxito de unas ciudades frente a otras en competencia por una posición ventajosa en las redes de relación nacional e internacional. En definitiva, la ciudad de León, que tuvo en el ferrocarril y en la industria tradicional su oportunidad para crecer y consolidarse como centro de actividades dinámico y organizador de un territorio de escala supraurbana, según el patrón del industrialismo, tras el proceso de desindustrialización y la obsolescencia ferroviaria que se imponen en la década de los años noventa del pasado siglo, encuentra en los recursos liberados una nueva oportunidad para regenerar la trama urbana, mejorar la conexión entre barrios, diversificar funciones y adquirir una imagen de ciudad moderna y competitiva. Un proceso, como se ha tratado de demostrar, dilatado, complejo y no exento de luces y sombras.

\section{Bibliografía}

ALCAIDE GONZÁLEZ, Rafael. El ferrocarril como elemento estructurador de la morfología urbana: el caso de Barcelona 1848-1900. Scripta Nova. Revista Electrónica de Geografía y Ciencias Sociales. [En línea]. Barcelona: Universidad de Barcelona, 1 de agosto de 2005, vol. IX, núm. 194 (65). http://www.ub.es/geocrit/sn/sn-194-65.htm.

ÁLVAREZ, Eduard y HERNÁNDEZ, Mireia. La infraestructura ferroviaria como condicionante del crecimiento de la trama urbana en ciudades medias catalanas a principios del siglo XX. In VI Congreso de Historia Ferroviaria, Vitoria: Fundación de los Ferrocarriles Españoles, 2012, p. 1-22.

ALVAREZ PALAU, Eduard, HERNÁNDEZ ASENSI, Mireia y TORT AYMERICH, Anna. Modelo morfológico de crecimiento urbano inducido por la infraestructura ferroviaria. Estudio de caso en 25 ciudades catalanas. Scripta Nova. Revista Electrónica de Geografía y Ciencias Sociales. [En línea]. Barcelona: Universidad de Barcelona, 1 de enero de 2016, vol. XX, n 527. http://www.ub.es/geocrit/sn/sn-527.pdf

ANDRÉS NISTAL, Pedro. El sector industrial en la ciudad de León y su entorno. León: 
Secretariado de Publicaciones de la Universidad de León, 1994.

ARTIGUES, Antoni et al (eds.). Los procesos urbanos postfordistas. VIII Coloquio y Jornadas de Campo de Geografía Urbana. Palma: Asociación de Geógrafos Españoles, 2006.

AYUNTAMIENTO DE LEÓN. Plan Especial de Protección del Conjunto Urbano de la Ciudad de León. Catálogo de Bienes y Elementos Protegidos. León, 28 de abril de 2000.

AYUNTAMIENTO DE LEÓN. Plan General de Ordenación Urbana de León. Aprobación Definitiva. León, 2004.

AYUNTAMIENTO DE LEÓN. Alta velocidad y ciudad. El Plan regional como nuevo modelo urbanístico. Exposición del 15 de junio al 15 de julio de 2006. León, 2006.

BARQUÍN, Rafael y PÉREZ, Pedro. La influencia del ferrocarril en el desarrollo urbano español (1860-1910). In VI Congreso de Historia Ferroviaria, Vitoria: Fundación de los Ferrocarriles Españoles, 2012.

BELLET, Carme y GUTIÉRREZ, Aaron. Ciudad y ferrocarril en la España del siglo XXI. La integración de la alta velocidad ferroviaria en el medio urbano. Boletín de la Asociación de Geógrafos Españoles, 2011, 55, 251-279.

BENITO DEL POZO, Paz. Pautas actuales de la relación entre industria y ciudad. Ería, Revista de Geografía, nº66, 2005, p. 57-70.

BENITO DEL POZO, Paz. Crecimiento y transformación del espacio industrial en León. Boletín de la Asociación de Geógrafos Españoles, n 49, 2009, p. 25-44.

BENITO DEL POZO, Paz y LÓPEZ TRIGAL. Lorenzo. Asentamientos industriales y tecnológicos en León. Aproximación a su estudio y valoración espacial. In BENITO, Paz (ed.). Áreas empresariales, suelo industrial y logística: análisis y procesos en el territorio. Cizur Menor (Navarra): Thomson Reuters-Aranzadi, 201 1, p. 143-170.

BERGERON, Louis y RONCAYOLO, Marcel. De la ville preindustrielle à la ville industrielle. Quaderni Storici, 1974, n 127, p. 827-876.

BRANDIS, Dolores y DEL RÍO, Isabel (2000). El ocaso de un espacio industrial central. El ensanche madrileño de Arganzuela a finales del siglo xx. In Lecturas Geográficas. Homenaje a José Estébanez. Madrid: Universidad Complutense, vol. II, p. 1029-1044.

BURRIEL, Emilio. La década prodigiosa del urbanismo español (1997-2006). Scripta Nova. Revista Electrónica de Geografía y Ciencias Sociales. [En línea]. Barcelona: Universidad de Barcelona, Vol, XII, 270 (64), 19 de septiembre de 2014. http://www. ub.es/geocrit/sn/sn-270/sn-270-64.htm

CALDERÓN, Basilio. El espacio industrial en la ciudad. Ería. Revista Cuatrimestral de Geografía, 1992, n² 29, p. 227-242

CALDERÓN, Basilio, GARCÍA, José Luis y PASCUAL, Henar. Patrimoine et compétivité urbaine: le cas des villes espagnoles. Sud-ouest européenrevue géographique des Pyrénées et du Sud-Ouest, 2005, nº 19, p. 121-130.

CAPEL, Horacio. La rehabilitación y el uso del patrimonio histórico industrial. Documents d'Anàlisi Geogràfica, 1996, n 29, p. 19-50.

CAPEL, Horacio. La morfología de las ciudades. I. Sociedad, cultura y paisaje urbano. 
Barcelona: Ediciones del Serbal, 2002.

CAPEL, Horacio. Los ferro-carriles en la ciudad. Redes técnicas y configuración del espacio urbano. Madrid: Fundación de los Ferrocarriles Españoles, 2011.

CAPEL, Horacio. El patrimonio: la construcción del pasado y del futuro. Barcelona: Ediciones del Serbal, 2014.

CARACCIOLO, Alberto (ed). Della città preindustriale alla città del capitalismo. Bologna: Societá editrice il Mulino, 1975.

CARAVACA, Inmaculada, MÉNDEZ, Ricardo. Trayectorias industriales metropolitanas: nuevos procesos, nuevos contrastes. EURE, 2003, nº 87, p. 37-50.

CARAVACA, Inmaculada y MENDEZ, Ricardo. Trayectorias industriales metropolitanas: nuevos procesos, nuevos contrastes. Revista Eure, 2003, Vol. XXIX, nº 87, p. 37-50

CONTI, Sergio. Recualificación y uso de los suelos industriales abandonados. In BENITO, Paz (ed.). Áreas empresariales, suelo industrial y logística: análisis y procesos en el territorio. Cizur Menor (Navarra): Thomson Reuters, 201 1, p. 15-32.

DANSERO, Egidio. Dentro ai vuoti. Dismissione industriale e trasformazione urbane a Torino. Torino: Edizione Librería Cortina, 1993.

DELGADO VIÑAS, Carmen (coord.). Espacios y paisajes urbanos: reflexionar sobre su presente para proyectar su futuro. Bilbao: Asociación de Geógrafos Españoles, 2010.

DELGADO VIÑAS, Carmen, JUARISTI, Joan y TOMÉ, Sergio (eds.). Ciudades y paisajes urbanos en el siglo XXI. Santander: Librería Estudio, 2012.

DIARIO DE LEÓN, 27/02/1992, p. 61.

DIARIO DE LEÓN, 02/03/1992, p. 7.

DIARIO DE LEÓN, 04/04/1992, p. 7.

EBRO, COMPAÑÍA DE AZÚCARES Y ALCOHOLES. 75 años de historia 1911-1986. Madrid: Ebro Compañía, 1986.

GÓMEZ GARCÍA, María Victoria. La metamorfosis de la ciudad industrial. Glasgow y Bilbao, dos ciudades con un mismo recorrido. Madrid: Talasa Ediciones, 2007.

GUTIÉRREZ, Javier. El tren de alta velocidad y sus efectos espaciales. Investigaciones Regionales, 2004, no 5, p. 199-221.

HERCE, Manuel. El negocio del territorio: evolución y perspectivas de la ciudad moderna. Madrid: Alianza, 2013.

HEWISON, Robert. The industry heritage. Britain in a climate of decline. London: Methuen, 1987.

JUNTA DE CASTILLA Y LEÓN. Plan PAHIS (2004-2012) del Patrimonio Histórico de Castilla y León. Valladolid, 2005.

LAYUNO, Ángeles. Las primeras "ciudades de la industria": Trazados urbanos, efectos territoriales y dimensión patrimonial. La experiencia de Nuevo Baztán (Madrid). Scripta Nova. Revista Electrónica de Geografía y Ciencias Sociales. [En línea]. Barcelona: Universidad de Barcelona, 20 de septiembre de 2013, vol. XVII, no 451. <http://www.ub.es/geocrit/sn/sn-451.htm>

LOIS, Rubén C. y PIÑEIRA, Ma José. Urban development processes in Spain from consolidated cities to urban regions with and overdensified housing market. 
In MIERZEJEWSA, Lidia y WDOWICKA, Magdalena (ed.): Contemporary Problems of Urban and Regional Development. Poznan: Ed. Bogucki, 201 1, p. 61-71.

LOIS, Rubén; PIÑEIRA, Ma José; VIVES, Sònia. El proceso urbanizador en España (1990-2014): una interpretación desde la geografía y la teoría de los circuitos de capital Scripta Nova. Revista Electrónica de Geografía y Ciencias Sociales. [En línea]. Barcelona: Universidad de Barcelona, l de julio de 2016, vol. XX, n 539. http://www. ub.es/geocrit/sn/sn-539.pdf

LÓPEZ TRIGAL, Lorenzo (coord.). La disponibilidad de recursos y el desarrollo industrial leonés. León: Departamento de Geografía de la Universidad de León y AGE-Grupo de Geografía Industrial, 1996.

LÓPEZ TRIGAL, Lorenzo. La ciudad de León y su alfoz. León: Servicio de Publicaciones de la Universidad de León, 1987.

LÓPEZ TRIGAL, Lorenzo (dir.). Las ciudades leonesas. Guía crítica desde la Geografía. León: Secretariado de Publicaciones de la Universidad de León, 2002.

MADERA, Encarnación y TOMÉ, Sergio. La operación ferroviaria y urbanística Cinturón Verde de Oviedo. Ería. Revista de Geografía, 1996, no 39-40, pp. 124-130.

MANERO, Fernando y GARCÍA CUESTA, José Luis (coords.). Patrimonio cultural $y$ desarrollo territorial. Cizur Menor (Navarra): Thomson Reuters-Aranzadi, 2016.

MARRÓN GAITE, Ma Jesús. La adopción y expansión de la remolacha azucarera en España (de sus orígenes al momento actual). Madrid: MAPA, Secretaría General Técnica, Serie Estudios, 1992.

MARTÍ-HENNEBERG, Jordi. Un balance del tren de alta velocidad en Francia. Enseñanzas para el caso español. Ería, Revista de Geografía 2000, nº. 52, p. 131-143.

MÉNDEZ, Ricardo y PASCUAL, Henar (coords.). Industria y ciudad en España: nuevas realidades, nuevos retos. Cizur Menor (Navarra): Thomson-Civitas, 2006.

NADAL, Jordi (dir.). Atlas de la industrialización de España. Barcelona: Crítica, 2003.

ONDATEGUI, Julio César. Las tecnópolis en España. Cizur Menor (Navarra): Thomson-Civitas, 2008.

PARDO ABAD, Carlos. Vaciado Industrial y nuevo paisaje urbano en Madrid. Antiguas fábricas y renovación de la ciudad. Madrid: Ediciones La Librería, 2004.

PARDO ABAD, Carlos. Estrategias de ordenación y gestión urbana del patrimonio industrial en España. Ciudad y Territorio. Estudios Territoriales, 2008, n 157, p. 473-498.

PRADA TRIGO, José. Avilés, una ciudad entre dos crisis. Actores locales y estrategias de revitalización. Avilés: Ediciones Azucel, 2014.

QUIRÓS LINARES, F. Las ciudades españolas en el siglo XIX. Salamanca: Ámbito Ediciones, 1991.

REGUERA, Antonio. La ciudad de León. Espacios y tiempos. León: Secretariado de Publicaciones de la Universidad de León, 1996.

REGUERA, Antonio. La tesis de las tres ciudades. Principios prácticos de la planificación urbana estatal y su aplicación a la ciudad de León. León: Secretariado de Publi- 
caciones de la Universidad de León, 2004.

RODRÍGUEZ, Arancha. Reinventar la ciudad: milagros y espejismos de la revitalización urbana. Revista de Relaciones Laborales, 2002, nº 6, p. 69-108.

ROMERO GONZÁLEZ, Joan. Construcción residencial y gobierno del territorio de España. De la burbuja especulativa a la recesión. Causas y consecuencias. Cuadernos Geográficos de la Universidad de Granada, 2010, nº 47, p. 17-46.

SÁNCHEZ, Simón; MÉNDEZ, Ricardo y PRADA, José. Avilés, entre el declive y la revitalización: ¿en la génesis de un nuevo modelo de desarrollo? Boletín de la Asociación de Geógrafos Españoles, 2012, n 60, p. 321-347.

SANTOS Y GANGES, Luis. Urbanismo y ferrocarril. La construcción del espacio ferroviario en las ciudades medias españolas. Madrid: Fundación de los Ferrocarriles Españoles, 2007.

SASSEN, Saskia. El reposicionamiento de las ciudades y regiones urbanas en una economía global: ampliando las opciones de políticas y gobernanza. EURE. Revista Latinoamericana de estudios urbanos y regionales, 2007, n 100, p. 9-34.

SEN RODRÍGUEZ, Carlos (2000): "Las transformaciones económicas de los siglo XIX y XX: la red viaria". In La Historia de León, vol. IV, Época Contemporánea, pp. 64-73. León, Secretariado de Publicaciones de la Universidad de León.

TATJER, Mercedes. La industria en Barcelona (1832-1992). Factores de localización y transformación en las áreas fabriles: del centro histórico a la región metropolitana. Scripta Nova. Revista electrónica de Geografía y Ciencias Sociales. Barcelona: Universidad de Barcelona, 1 de agosto de 2006, vol. X, núm. 218 (46). http://www. ub.es/geocrit/sn/sn-218-46.htm

TOMÉ, Sergio. Oviedo, paisajes urbanos en desaparición. Oviedo: Departamento de Geografía de la Universidad de Oviedo, 2001.

UNIVERSIDAD DE LEÓN. Inventario de Instalaciones Industriales Abandonadas. León. León, 2002 (inédito).

VALENZUELA, Manuel (coord.). Las ciudades españolas en la encrucijada: entre el boom inmobiliario y la crisis económica. Madrid: Real Sociedad Geográfica y Asociación de Geógrafos Españoles, 2013.

VELTZ, Pierre. Mundialización, ciudades y territorio. Barcelona: Ariel, 1999.

(c) Copyright: Paz Benito del Pozo, Francisco Díez Vizcaíno, 2017

(C) Copyright Scripta Nova, 2017.

Ficha bibliográfica:

BENITO DEL POZO, Paz; DÍEZ VIZCAÍNO, Francisco. Estrategias de renovación de barrios industriales en ciudades medias españolas. La experiencia de León. Scripta Nova. Revista Electrónica de Geografía y Ciencias Sociales. [En línea]. Barcelona: Universidad de Barcelona, 15 de marzo de 2017, vol. XXI, n 560. [ISSN: 1138-9788]. 